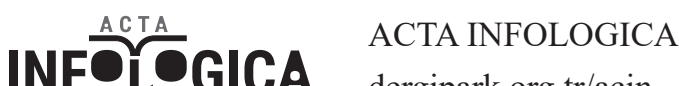 \\ dergipark.org.tr/acin
}

İSTANBUL

UNIVERSITY

P R E S S

\section{Medikal Görüntü İşlemede Derin Öğrenme Uygulamaları}

\section{Deep Learning Applications in Medical Image Processing}

\author{
Ayșe Gül Eker ${ }^{1}$ (D), Nevcihan Duru ${ }^{2}$ (1)
}

1 (Dr. Öğr. Üyesi), Kocaeli Üniversitesi,

Mühendislik Fakültesi, Bilgisayar Mühendisliği Bölümü, Kocaeli, Türkiye

${ }^{2}$ (Prof. Dr.), Kocaeli Üniversitesi, Havacılık ve Uzay Bilimleri Fakültesi, Havacılık Elektrik

Elektroniği Bölümü, Kocaeli, Türkiye

ORCID: A.G.E. 0000-0003-0721-2631; N.D. 0000-0003-2154-7067

\section{Corresponding author:}

Ayşe Gül EKER

Kocaeli Üniversitesi, Mühendislik Fakültesi,

Bilgisayar Mühendisliği Bölümü, Kocaeli,

Türkiye

E-mail address: nduru@kocaeli.edu.tr

Submitted: 25.04 .2021

Revision Requested: 05.07 .2021

Last Revision Received: 27.07.2021

Accepted: 27.07.2021

Published Online: 06.10.2021

Citation: Eker A. G. Ve Duru, N. (2021). Medikal görüntü işlemede derin öğrenme uygulamaları. Acta Infologica. Advance online publication. https://doi.org/10.26650/acin.927561
ÖZ

Manyetik rezonans görüntüleme (MRI), bilgisayarlı tomografi (BT), pozitron emisyon tomografisi (PET), mamografi, ultrason ve röntgen gibi tıbbi görüntüleme teknikleri uzun yıllardan beri hastalıkların teşhisi, tanısı ve tedavisi için kullanılmıştır. Ancak hastalıkların daha erken teşhisi, uzmanların yoğunluğunu azaltma, çakışan uzman görüşlerini karara bağlama gibi nedenlerle, bu alanda makine öğrenmesi yöntemlerinden yararlanılmaktadır. Veri miktarının artması ile makine öğrenmesi yöntemleri görüntü işleme alanında yetersiz kalmış, gelişen matematiksel modeller ve donanımsal cihazlar sayesinde derin öğrenme bu alanda kendine geniş bir yer edinmiştir. Bu çalışmada derin öğrenme yöntemlerinin medikal görüntü işleme alanında uygulanması incelenmiştir. Segmentasyon, sınıflandırma ve hastalık teşhisi, görüntü oluşturma, dönüştürme ve iyileştirme alanlarında yapılan çalışmalardan oldukça güncel örnekler sunulmuş, yapılan çalışmalarda kullanılan algoritmalar kısaca açıklanmıştır. Ayrıca BraTS 2020 veri seti üzerinde derin öğrenme ile beyin tümör segmentasyonu gerçekleştirme denenmiş, sonuç olarak \%86 dice benzerlik oranı ve $\% 80$ hassasiyet değeri elde edilmiştir. Bu çalışmanın medikal görüntüler üzerinde derin öğrenme yöntemleri ile yapılacak farklı çalışmalara yol gösterecek bir kaynak olması hedeflenmiştir. Anahtar kelimeler: Derin Öğrenme, Görüntü İşleme, Medikal Görüntü, Evrişimli Sinir Ağları, Çekişmeli Üretici Ağlar, Bölütleme, Sınıflandırma, Görüntü İyileştirme

\begin{abstract}
Medical imaging techniques such as magnetic resonance imaging (MRI), computed tomography (CT), positron emission tomography (PET), mammography, ultrasound and x-ray have been used for the diagnosis and treatment of diseases for many years. However, machine learning methods are used in this field for reasons such as earlier diagnosis of diseases, reduce the workload of doctors, and adjudicate conflicting expert opinions. With the increase in the amount of data, machine learning methods have remained insufficient in the field of image processing. Thanks to the developing mathematical models and hardware devices, deep learning has taken a wide place in this field. In this study, the application of deep learning methods in the field of medical image processing has been examined. Very recent examples are presented from studies in the fields of segmentation, classification and disease diagnosis, image generation, image transformation and image enhancement. The algorithms used in the studies are briefly explained. In addition, brain tumor segmentation with deep learning was tried on the BraTS 2020 dataset, and as a result, a dice similarity rate of $86 \%$ and a sensitivity value of $80 \%$ were obtained. Our aim is for this study to guide different studies on medical images with deep learning methods and serve as a basic resource in this field. Keywords: Deep Learning, Image Analysis, Medical Image, Convolutional Neural Network, generative Adversarial Network, Segmentation, Classifying, Image Enhancement
\end{abstract}




\section{GíRIŞ}

Uzun yıllardan beri, manyetik rezonans görüntüleme (MRI), bilgisayarlı tomografi (BT), pozitron emisyon tomografisi (PET), mamografi, ultrason ve röntgen gibi tıbbi görüntüleme teknikleri erken teşhis, tanı ve hastalıkların tedavisi için kullanılmıştır. Kliniklerde tıbbi görüntülerin yorumlaması ise çoğunlukla radyologlar ve hekimler gibi uzmanlar tarafından yapılmaktadır. Ancak, patolojideki geniş varyasyonlar ve gerçek uzmanların potansiyel yorgunluğu, insan hatasına yatkın ve uzmandan uzmana farklılık gösterebilen durumlar göz önüne alındığında, bilgisayar destekli müdahalelerden yararlanmanın oldukça gerekli olduğu söylenebilir. Geleneksel makine öğrenmesi yöntemlerini bu alanda kullanmak ise karmaşık problemlerin çözümünde yetersiz kalmaktadır. Hızlı işlemecilerin gelişmesi ile bu alanda derin öğrenme yöntemlerinden yararlanarak medikal görüntülerin doğru ve verimli bir şekilde kullanılması ile hastalık teşhisi, tedavisi ve hastalıkların önlenmesi gibi alanlarda doktorlara destek olunması mümkündür.

Son 20 yıla kadar insanların makinelere karşı üstünlüklerinden biri, gösterilen bir görüntüden örüntüyü tanıyabilmeleri ve ayırt edebilmeleri idi. Gelişmiş derin öğrenme algoritmaları sayesinde artık makineler de örüntüleri tanıyabiliyor ve yorumlayabilir hale gelmiştir. Son yıllarda oldukça popüler olan derin öğrenme, makine öğrenmesinin bir alt alanıdır. Makine öğrenmesi ise yapay zekânın bir alt alanıdır. Yapay zekâ; makinelerin insan beyninin çalışmasını taklit ederek karar verme ve tahmin etme gibi çözülmesi zor olan problemlerin çözümüne imkân tanıyan bir bilim dalıdır [1]. Dolayısıyla derin öğrenme de aslında yapay zekâda olduğu gibi; beynin yapısından ve işleyişinden esinlenilen bir dizi algoritmaya dayanmaktadır. Derin öğrenme; medikal, robotik, resim tanıma ve resim üretme, otonom araçlar, doğal dil işleme, uzay ve savunma sanayi gibi pek çok alanda kullanılarak veri biliminde oldukça popüler alanlardan biri haline gelmiştir.

Derin öğrenme, bir yapıdaki özellikleri, insan gücü olmadan verilerden otomatik olarak çıkardığı derin bir sinir ağ kullanarak öğrenmektedir. Burada önemli olan yeterli miktarda verinin mevcut olmasıdır. Derin öğrenme sistemleri klasik makine ögrenmesi yöntemlerinden farklı olarak daha fazla deneyimle, çok sayıda veri üzerinde çalışır ve yüksek bir performans sunar. Ayrıca derin öğrenme, bir ağa ham veriler ile sınıflandırma gerçekleştirilmesi gereken bir görevin verildiği "uçtan uca öğrenme" gerçekleştirir ve bunu otomatik olarak nasıl yapacağını da kendi öğrenir.

Yapay zekâ medikal alanda daha önce 1990 yıllarda kullanılmış ve bazı başarısız sonuçlar elde edilmiştir. Bunun nedenleri arasında yeterince gelişmiş olmayan donanımsal cihazlar ve modeller bulunur. Bu dönemlerde yapay zekânın kışı yaşanmıştır ve bunun sonucunda da bazı hekimler sağıı alanında yapay zekâ kullanılmasına karşı bir önyargıya sahip olmuşlardır. Ancak günümüzde derin öğrenmenin başarısı sayesinde, hekimlerin ve mühendislerin iş birliği yapmasıyla pek çok çalışma gerçekleştirilmiş ve son derece başarılı sonuçlar elde edilmiştir.

$\mathrm{Bu}$ yazıda medikal görüntülemede kullanılan derin öğrenme yöntemleri kısaca anlatılarak literatürde bulunan çalışmalar; sınıflandırma ve hastalık teşhisi, segmentasyon, görüntü oluşturma ve dönüştürme, görüntü iyileştirme alanlarında sunulacaktır.

\section{MEDIKKAL GÖRÜNTÜLERDE KULLANILAN DERIN ÖĞRENME ALGORITTMALARI}

Derin öğrenme algoritmaları; görüntü işleme, metin analizi gibi pek çok alanda kullanılan oldukça popüler yöntemlerdir. Bu çalışmada, yalnızca medikal görüntüler üzerinde kullanılan algoritmalar kısaca açıklanmıştır. Bu algoritmalar; sınıflandırma, segmentasyon gibi görevlerde sıklıkla kullanılan ‘Evrişimli Sinir Ağları’ ve görüntü oluşturma, iyileştirme gibi alanlarda kullanılan ‘Çekişmeli Üretici Ağlar' dır.

\subsection{Evrişimli Sinir Ağları}

Görüntü analizi için bugüne kadarki en başarılı model türü olan Evrişimli Sinir Ağları (Convolutional Neural Network kısaca CNN) bir görüntü sunumu ve sınıflandırma tekniğidir. CNN'ler, girdileri evrişim filtreleriyle küçük alanlara dönüştüren birçok katman içerir. CNN'ler üzerindeki çalışmalar aslında yetmişli yılların sonlarına dayanmaktadır Fukushima 1980'de "denetimsiz öğrenme" ile kendi kendini organize edebilen bir ağ yapısı geliştirmiştir. Fukushima’nın ağları günümüzdeki modern ağlara oldukça benzeyen bir yapıdadır. Ardından 1995 yılında Lo ve diğerleri tarafından medikal görüntü analizine uygulanmıştır. Derin sinir ağ mimarilerindeki en temel eksiklik çoklu katmanların hatalarının geri yayılımıdır. Çeşitli 
denemeler olsa da geri yayılım algoritmaları için ilk başarılı derin sinir ağı mimarisini Yann LeCun ve ekibi posta kutusu üzerindeki yazıları tanımak için geliştirmişlerdir ve böylece ilk başarılı gerçek dünya uygulamalarını LeNet’te (1998) görmüşlerdir. Ancak bu ilk başarılara rağmen, CNN'lerin kullanımı, derin ağları verimli bir şekilde eğitmek için çeşitli yeni teknikler geliştirilinceye ve çekirdek hesaplama sistemlerinde ilerlemeler kaydedilinceye kadar ivme kazanmamıştır. Dönüm noktası ise Krizhevsky ve diğ. (2012) ImageNet yarışmasına. AlexNet [2] adı ile önerilmiş olan CNN algoritmasının, bu rekabeti büyük bir farkla kazanması olmuştur. Bu noktadan sonra ise hız kesmeden ilerleyişine devam etmiş̧ir.

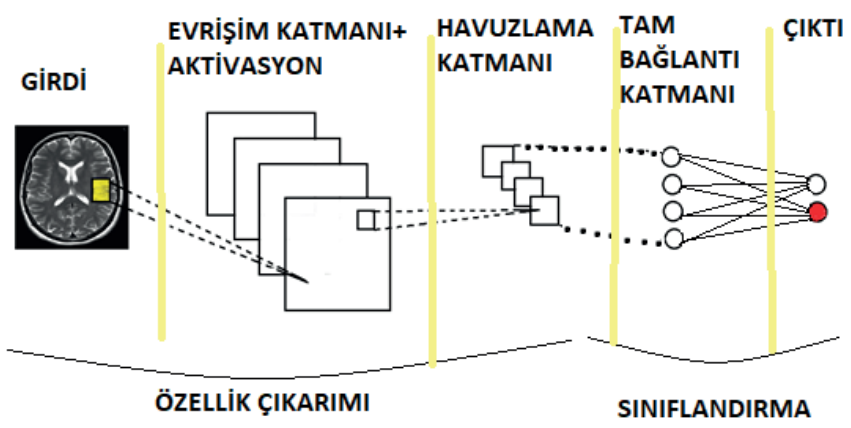

Şekil 1. Evrişimli Sinir Ağı Mimarisi

CNN'ler görsel nitelikler arasındaki tüm özellikleri bulabilmek için birden fazla katmana ihtiyaç duyarlar. CNN'nin temel yapısı; Şekil 1'de göründüğü gibi girdi, evrişim katmanı, aktivasyon katmanı, havuzlama katmanı ve tam bağlantı katmanı ve çıktı şeklindedir. Girdi verisi ham bir şekilde ağa sunulur. Girdinin boyutu ve çözünürlüğü oldukça önemlidir. Büyük boyutta ve yüksek çözünürlükte bir girdi eğitim süresini uzatabilir ancak aynı zamanda başarıyı arttırabilir. Evrişim katmanı, ağdaki en temel katmandır ve dönüşüm katmanı olarak da bilinir. Girdi görüntüsünün üzerinde bir filtre dolaştırılarak yeni bir matris çıkarılır. Burada filtreler önemli rol oynar. Bu filtreler sayesinde kendinden önce gelen görüntüye konvolüsyon işlemi uygulanarak bir çıkış verisi oluşturur. Böylece bir özellik haritası elde edilmiş olur. Eğitim esnasında kullanılan filtrelerin katsayıları her adımda yinelenir [3]. Özellik haritası; giriş verilerinin farklı özelliklerinin çıkarıldığı ve ağırlık paylaşımı ile modelin karmaşıklığının azaltıldığı haritalardır ve ağın eğitilmesini kolaylaştırırlar. Havuzlama katmanı isteğe bağlı kullanılmakla birlikte temel amaç ağın parametre sayısını ve boyutlarını azaltmaktır [4]. Boyuttaki azalma sonucu bilgi kaybı yaşanması kaçınılmazdır ancak bu bilgi kaybı aslında ağın yararınadır. Hesaplama yükünün azalması ilk yararıdır. İkinci yararı ise ağdaki ezberlemenin minimuma iniyor olmasıdır. Böylece havuzlama katmanı da özellik çıkarılmasında ikinci bir rol oynamış olur. Son katman ise tam bağlantı katmanıdır. Burada önceki katmanlardan gelen veriler ağılıklandırılarak birleştirilir Ardından bir kayıp fonksiyonu sayesinde nöronlara eğitim boyunca verilecek en uygun ağırlık değerleri bulunur [5]. Bu katmanda çeşitli aktivasyon fonksiyonları kullanılarak sınıflandırma için olasılık değerleri hesaplanmaktadır. Bu nedenle CNN, tıbbi görüntü sınıflandırması için genellikle ilk tercihtir. Ancak daha iyi çalışabilmesi için genelde etiketli görüntülerden oluşan büyük boyutlu bir veri kümesi gerekmektedir.

CNN algoritmaları görüntü işlemede olduğu gibi medikal görüntü işlemede de oldukça önemli bir yere sahiptir. Segmentasyon, sınıflandırma, teşhis, dönüşüm gibi problemlerde geliştirilen çeşitli mimariler kullanılmaktadır.

\section{2. Çekişmeli Üretici Ağlar}

Generative Adversarial Network yani kısaca GAN olarak bilinen Çekişmeli Üretici Ağ modelleri, görüntü veri kümesinin genişletilmesinde, yüksek çözünürlüğe sahip görüntü elde etmede, bir görüntüdeki doku/desenin başka bir görüntüye transferinde kullanılmaktadır.2014 yılında önerilen GAN [6] lar için geliştiricilerinden Goodfellow; ağın mantı̆̆ını anlatmak için şu metaforu kullanmaktadır: "Üretici, gerçek tablolara benzer tablolar yapmaya çalışan bir 'kalpazan' takımı iken, Ayırıcı ise gerçek ile sahteyi anlamaya çalışan 'dedektif' ekibine benzemektedir. Bu algoritmanın amacı içerisinde bulunan iki modeli (üretici-generator ve ayırıcı-disciminator) eş zamanlı olarak eğitmektir. Şekil 2'de 'Çekişmeli Üretici Ağ Mimarisi' sunulmuştur. Bu şekilde görülen başlangıçta rastgele halde bulunan gürültüleri (genellikle Gauss Gürültüleri), üretici model anlamlı bir görüntüye dönüştürmeye çalışmaktadır. Ayırıcı model ise bir eleştirmen rolünde, üreticiden gelen resmin sahteliğini 
kanıtlamaya çalışır. Üreticiden gelen sahte resim ile eğitim setindeki gerçek resmi ayırt etmeye çalışır.Bu klasik bir ikili sınıflandırma problemidir.Çıktı olarak gerçek veya sahte olarak tek bir değer sunar. Üretici, ayırıcıdan gelen bu geri bildirim ile parametrelerini güncelleyerek bir sonraki denemesinde gerçeğe daha yakın görüntü üretmeye çalışır ve bunu tekrar ayırıcıya sunar. Bu iki sinir ağı sürekli bir çekişme halindedir ve bir süre sonra bu çekişmeden beslenen ayırt edici model; sahte ve gerçek verileri daha iyi ayırt etmeye başlarken, üretici model de gerçeğe daha yakın veriler üretmeye başlar. Ian Goodfellow bu iki yapıyı polis ve kalpazan metaforu ile anlatmıştır. Kalpazan (üretici) sahte para üretmektedir ve Polis(Ayırt Edici) sahte paraları ayırt etmektedir. Zamanla polis sahte paraları daha iyi ayırt etmeye başlar ve kalpazanda gerçeğe daha yakın sahte para üretmeye başlar. Sürekli yarış halinde olan bu iki sinir ağ yapısının oluşturuduğu mimariye çekişmeli veya düşmanca üretici ağlar denilmektedir.

Zaman içerisinde GAN mimarisinin farklı varyasyonları geliştirilmiştir. Bir görüntüyü farklı bir konsepte dönüştürme amacıyla geliştirilmiş, iki adet iç içe geçmiş gan modelinden oluşan CycleGAN [7], genellikle görüntü verileri ile çalışılırken kullanılan ve GAN modelinde üretici ve ayırt edici ağların ikisinde de evrişimli ağların kullanılmasını öneren DCGAN[8], resimden resime dönüşümlerde en popüler yaklaşımlardan biri olan, ayırt edici ağda kullanılan PatchGan ile gerçek ve sahte resimleri ayırt etme sırasında bütün resim yerine resmi küçük parçalara bölerek bu parçalar üzerinde değerlendirme yapan pix2pix[9], GAN modelinde kullanılan kayıp fonksiyonunu 'Wasserstein Distance' denilen uzaklık formülü değiştirerek daha dengeli eğitim ve daha benzer sonuçlar üretmeyi amaçlayan WGAN[10] bunlardan bazılarıdır.

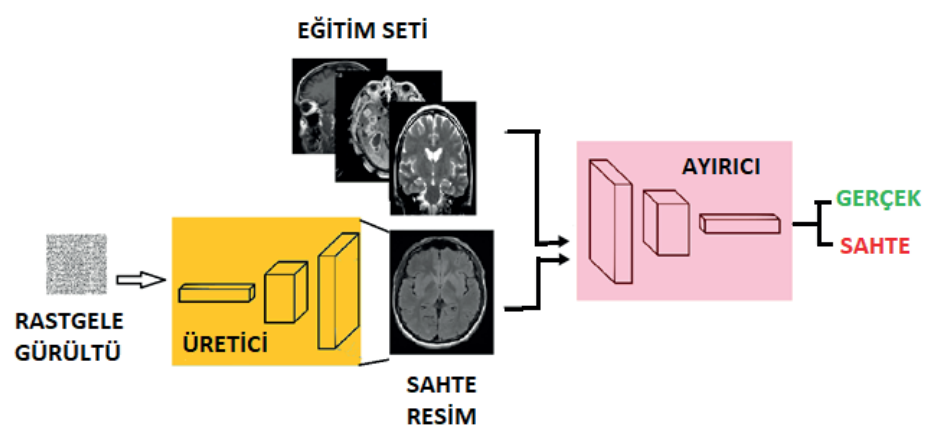

Şekil 2. Çekişmeli Üretici Ağ Mimarisi

\section{DERIN ÖĞRENMENIN MEDİKAL GÖRÜNTÜLERDE UYGULAMALARI}

Bu bölümde sırayla; derin öğrenme ile medikal görüntülerde segmentasyon uygulamaları, medikal görüntülerde sınıflandırma ve hastalık teşhisi uygulamaları, medikal görüntü oluşturma ve dönüştürme uygulamaları, medikal görüntü iyileştirme uygulamaları sunulacaktır.

\subsection{Derin öğrenme ile medikal görüntülerde segmentasyon}

Segmentasyon, bir diğer adıyla bölümleme ya da bölütleme; bir görüntüyü farklı özelliklerin tutulduğu anlamlı bölgelere ayırmaktır. Yani, her piksel için etiketler çıkartılır ve bu etiketlere dair tahminler yapılarak birtakım çıkarımlarda bulunulur. Medikal görüntülerde de tanı ve tedavinin ilk ve oldukça kritik bir bileşenidir ve homojen alanları ayırmak için yaygın olarak kullanılmaktadır [11]. BT veya MR görüntülerinde; organların veya lezyonların piksellerini tanımlayan tıbbi görüntü segmentasyonu, bu organların ve lezyonların şekilleri ve hacimleri hakkında kritik bilgiler sunmak konusunda oldukça önemli yere sahiptirler. Daha önceleri bu görevler çeşitli filtreler ve çeşitli matematiksel formüllerin uygulanması ile gerçekleştirilirken son yıllarda derin öğrenmeye dayalı teknikler büyük ilgi görerek bu alanda sıklıkla kullanılmaya başlanmıştır.

CNN algoritmaları bu alanda kullanılan temel derin öğrenme algoritmalarıdır. Bilgisayar destekli tanı sistemlerinde analize edilmek üzere medikal görüntülere segmentasyon uygulanması oldukça değerlidir. Bunun yanı sıra sınıflandırma çalışmalarının bir kısmı da segmentasyona dayanmaktadır. Önce segmentasyon gerçekleştirilerek tümör veya lezyon tespit edilir ve ardından türü sınıflandırılır. 
Segmentasyonun derin öğrenme ile ilgili bazı örnekler; Zheng ve diğ. (2017) BT taramalarında patolojik böbrek segmentasyonu ile böbreğin kabaca konumunu bulma [12], Pan ve diğ. (2018) tamamen evrişimli sinir ağı modeli ile patoloji ve mikroskop görüntülerinde çekirdekleri sağlam ve doğru bir şekilde tespit etme [13], Farag ve diğ. (2017)çeşitli analiz ve cerrahi sırasında yardım için bilgisayar destekli tanı sistemlerine bir girdi olarak sunulan dalak, karaciğer gibi abdominal organlardan pankreasın BT görüntülerinde segmentasyonudur [14].

Daha sonra CNN üzerinde bazı iyileştirmeler yapılarak segmentasyonun daha etkili gerçekleştirilmesi sağlanmıştır. Long ve diğerleri tarafından geliştirilen tamamen evrişimli ağda (Fully Connected Network-FCN) [15], son tam bağlı katman, tamamen evrişimli bir katmanla değiştirilmiştir ve böylece ağın yoğun ve akıllı bir piksel tahminine sahip olması sağlanmıştır. Nie ve diğ. (2016) Daha önce CNN ile yapılan bir çalışmayı aynı veriseti üzerinde aynı paramatreleri kullanarak FCN ile gerçekleştirerek daha iyi sonuçlar alındığını kanıtlamışlardır [16]. Zhou ve diğ. (2017) Abdominal organlar için aynı anda 19 farklı organın segmentasyonunu 2.5D FCN ile 3 boyutlu BT görüntülerinde sağlamışlardır [17]. Sun ve diğ. (2021) beyin tümörü segmentasyonu için Mr görüntülerinde 3D FCN kullanmışlardır [18].

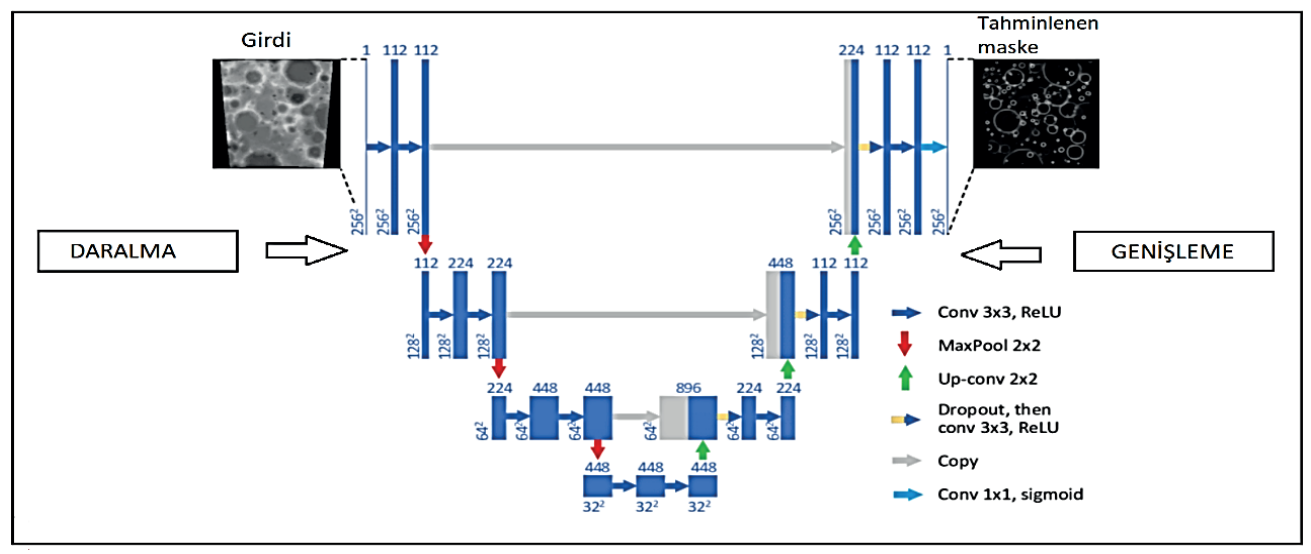

Şekil 3. U-net Mimarisi

Ronneberger ve diğ. (2015), FCN fikrini bir adım daha ileri götürerek ve biyomedikal görüntü segmentasyonu için geliştirdikleri U-net mimarisini sunmuşlardır [19]. Şekil 3' te mimarisi sunulan U-net, iki ana bölümden oluşmaktadır ve 'U' harfine benzer biçimdeki mimarisi nedeniyle bu adı almıştır. İlk bölüm Daralma bölümüdür ve klasik evrişimli sinir ağı mimarisindedir.'relu’ aktivasyon fonksiyonu ve 'havuzlama' katmanlarından oluşur. Genişleme bölümü U-net modelinin en önemli kısmıdır. Daralma bölümünden gelen özellikler genişleme bölümüne gönderilir ve bu bölümde genişletilerek girdi ile aynı boyutta ve çözünürlükte görüntü üretilmesi sağlanır. FCN`lere benzer şekilde; evrişimli katmanlardan, aşağı örnekleme(up-sampling) katmanlarından ve yukarı örnekleme(down-sampling) katmanlarından oluşur. Ancak FCN`lerden farklı olarak, U-net te aşağı örnekleme katmanlarının ve yukarı örnekleme katmanlarının ve aralarındaki evrişim katmanlarının sayısı aynıdır. Ek olarak, U-net, her bir alt örnekleme katmanı çiftini ve yukarı örnekleme katmanını bağlamak için atlama bağlantı işlemini kullanır. Bu da uzamsal bilgilerin doğrudan çok daha derin katmanlara uygulanmasını ve daha doğru bir segmentasyon yapılmasını sağlar. U-Net yapısını daha zengin uzaysal bilgilerle güçlendirmek amacıyla, Cicek ve diğ. (2016) bir 3D U-Net modeli geliştirdi [20]. Önerilen model, bazı 2D açıklamalı dilimlerden yoğun hacimsel segmentasyon oluşturmayı başardı. A $\breve{g}$, hem seyrek olanlardan yeni örneklerin notlarını hem de seyrek açıklamalı örneklerin yoğunlaştırılmasını gerçekleştirebilmiştir. Kısaca ağ, tüm operasyonu 3 boyutlu olarak gerçekleştirebilecek şekilde yeniden tasarlanmışıtır. Ancak U-net, bazı kafa karıştırıcı arka plan alanlarının yanı sıra dokunma veya üst üste binen hücreleri ayırt etmek gibi bazı konularda eksiklikleri vardır. U-net in medikal görüntüler üzerinde kullanılmak üzere geliştirilen pek çok varyantı mevcuttur. U-net++, (Zhou ve diğ. 2018)[21], RU-Net ve R2U-Net (Alom ve diğ. 2018)[22], MultiResUNet (Ibtehaz ve Rahman 2020)[23], SAUnet (Sun J. Ve diğ. 2020)[24], ASCU-Net (Tong ve diğ. 2021)[25], MRFU-Net (Li C. Ve diğ. 2021)[26] bunlardan bazılarıdır. 


\subsubsection{Derin Öğrenme ile Beyin Mr Görüntülerinde Tümör Segmentasyonu Uygulaması}

U-net mimarisi kullanılarak BraTS 2020 veri seti üzerinde beyin tümör segmentasyonu gerçekleştirilmiştir. Kısa zamanlamalı radyo frekansları kullanılarak alınan ve yaygın olarak kullanılan T1-Ce sekansındaki Mr görüntülerinde segmentasyon gerçekleştirilmiştir ve bu sekansta ödemli yapı değil çekirdek tümör (tümör merkezi) belirgin durumdadır. Çalışmada da çekirdek tümörün segmentasyonunu gerçekleştirmek amaçlanmıştır.

BraTS veri setindeki MR görüntüleri NIFTI formatındadır. 3 farklı eksende (axial, coronal, sagital), $240 * 240$ piksel boyutunda beyin MR görüntüleri ve uzmanlar tarafından etiketlenmiş tümör görüntüleri bulunmaktadır. Mr görüntülerinde piksel yoğunluğunun dağılımında eşitsizlikler gözlemlendiği için model direkt olarak eğitilmemiş, bir önişleme ile normalizasyon yapılmıştır. Tümör merkezinin koordinatları bulunarak bu koordinat merkez olarak kullanılıp görüntüler üzerinde kırpma gerçekleştirilmektedir. 240*240 boyutundaki MR görüntüleri üzerinde $64 * 64$ bir çerçeve ile x ve y koordinatları sırayla dolaşılarak tüm görüntü taranmaktadır. Bu işlemin amacı görüntü üzerinde bulunan yoğunluğa göre genlik değeri en yüksek olan 64*64 piksellik bölgeyi tümör olma olasılığı en yüksek bölge olarak değerlendirip seçmek ve burada kırpma gerçekleştirmektir. Tümörün boyutuna göre birden fazla parça halinde kırpma gerçekleştirilebilir. Kırpılan T1ce MR görüntüleri ve radyoloji uzmanları tarafından manuel olarak çıkarılmış segmentasyon görüntüleri ile model eğitilmiştir.

Eğitim sırasında optimizasyon algoritması olarak 'Adam', metrik olarak ise 'Dice Benzerlik Oranı' kullanılmıştır. Dice Benzerlik Oranı iki veri arasındaki benzerliği ölçen istatistiksel bir araçtır ve özellikle segmentasyon alanında sıklıkla kullanılmaktadır. Eğitim tamamlandığında doğrulama için Dice Benzerlik Oranı: \%86, Hassaslık Değeri ise \%80 çıkmıştır.

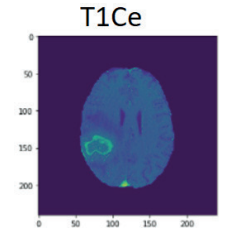

$\mathrm{T} 1 \mathrm{Ce}$

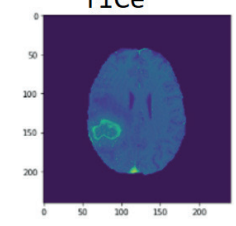

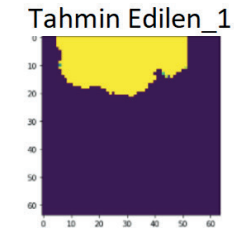
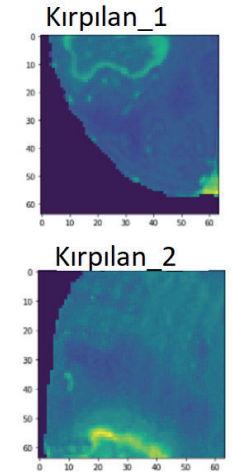

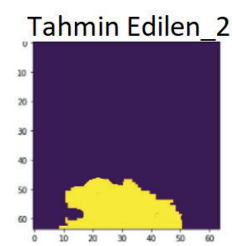

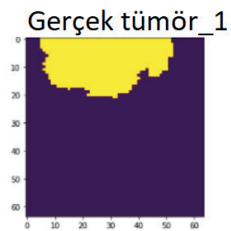

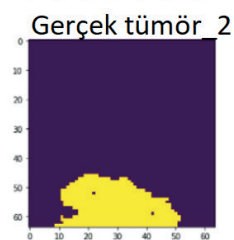

Şekil 4. U-net ile beyin tümör segmentasyonu örnek sonuçlar

Şekil 4- te modelin eğitimi sonucu daha önce modele sunulmayan bir Mr görüntüsü üzerinde kırpma gerçekleştirilmesi sunulmuştur. Kırpılan parçalar üzerinde modelin tahmin ettiği segmentasyon parçaları ve gerçek segmentasyon parçaları gösterilmiştir. U-net modelinin etiketli parçalara oldukça benzer görüntü ürettiği görülmektedir. 
Tablo 1

Tablo Beyin Tümör Segmentasyonu konusunda araştırmacılar tarafindan kullanılan farklı teknikleri ve başarı oranlarını göstermektedir.

\begin{tabular}{|c|c|c|c|c|c|c|c|}
\hline Yıl, Yayın & Veri Seti & Teknik & Gözlemler & \multicolumn{4}{|c|}{ Başarı değerleri } \\
\hline \multirow[t]{2}{*}{$\begin{array}{l}2019,[27] \\
(\mathrm{ACM})\end{array}$} & \multirow[t]{2}{*}{ BraTS 2015} & \multirow[t]{2}{*}{$\begin{array}{l}\text { Derin } \\
\text { Öğrenme, } \\
\text { CNN }\end{array}$} & \multirow[t]{2}{*}{$\begin{array}{l}\text { Çeşitli tümör türlerinin tanımlanması için } \\
\text { MR görüntüleri üzerinde evrişimli sinir } \\
\text { ağları ile çalışma yapılmıştır. }\end{array}$} & \multicolumn{4}{|c|}{$\begin{array}{l}\text { Dice Benzerlik Oranı - \%86.7 } \\
\text { Doğruluk (Accuracy) - \%98.33 }\end{array}$} \\
\hline & & & & & Benzerl & Oranlar1: & \\
\hline \multirow{9}{*}{$\begin{array}{l}\text { 2019,[28] } \\
\text { (IEEE) }\end{array}$} & \multirow{9}{*}{$\begin{array}{l}\text { BraTS-2013 } \\
\text { BraTS-2015 } \\
\text { BraTS-2018 }\end{array}$} & \multirow{9}{*}{$\begin{array}{l}\text { Derin } \\
\text { Öğrenme, } \\
\text { CNN }\end{array}$} & \multirow{9}{*}{$\begin{array}{l}\text { Iki aşamadan oluşan mimarinin ilk } \\
\text { aşamasında etiketlerin yerel bağım- } \\
\text { lılıklarını hesaba katmak ve kabaca } \\
\text { segmentasyon gerçekleştirmek için çok } \\
\text { kademeli bir evrişimli sinir ağ mimarisi } \\
\text { geliştirilmiştir (multicascaded convolution- } \\
\text { al neural network-MCCNN). İkinci aşama- } \\
\text { da daha hassas segmentasyon sağlamak } \\
\text { üzere bazı sahte çıktıları ortadan kaldırmak } \\
\text { için uzamsal bağlamsal bilgi dikkate } \\
\text { alınarak tam bağlantılı koşullu rastgele } \\
\text { alanlar (fully connected conditional random } \\
\text { fields CRFs) kullanılmıştır. }\end{array}$} & & $\begin{array}{c}\text { BraTS } \\
2013 \\
\end{array}$ & $\begin{array}{c}\text { BraTS } \\
2015 \\
\end{array}$ & $\begin{array}{c}\text { BraTS } \\
2018\end{array}$ \\
\hline & & & & & $\% 89$ & $\% 87$ & $\% 88.24$ \\
\hline & & & & $\begin{array}{l}\text { Çekirdek } \\
\text { tümör }\end{array}$ & $\% 82$ & $\% 76$ & $\% 74.81$ \\
\hline & & & & $\begin{array}{l}\text { Genişlemiş } \\
\text { tümör }\end{array}$ & $\% 77$ & $\% 75$ & $\% 71.78$ \\
\hline & & & & \multicolumn{4}{|c|}{ Hassaslik: } \\
\hline & & & & & $\begin{array}{c}\text { BraTS } \\
2013 \\
\end{array}$ & $\begin{array}{c}\text { BraTS } \\
2015 \\
\end{array}$ & $\begin{array}{c}\text { BraTS } \\
2018 \\
\end{array}$ \\
\hline & & & & Tüm tümör & $\% 90$ & $\% 87$ & $\% 90.74$ \\
\hline & & & & Çekirdek tümör & $\% 84$ & $\% 74$ & $\% 76.21$ \\
\hline & & & & $\begin{array}{l}\text { Genişlemiş } \\
\text { tümör }\end{array}$ & $\% 86$ & $\% 80$ & $\% 86.84$ \\
\hline
\end{tabular}

Tüm tümörü segmentlere ayırmak ve ardından beyin MR görüntüsünde çekirdek tümör bölgesi ve diğer bölgeleri ayırt edebilmek için cycleGAn mimarisinin genişletilmiş hâli olan eşleştirilmemiş çekişmeli eğitim yaklaşımı sunulmuştur. Önerilen
2020,[29]

(Elsevier)

2020, [30]

(Springer)

\section{BraTS-2015 \\ BraTS-2017}

Öğrenme,

CycleGAN der-decoder network) kalıntı ve yansitma ilkeleri kullanılarak tasarlanmıştır. Eğitim için çok daha az miktarda veri gerektirdiği belirtilmiştir.

tümör

\section{Dice Benzerlik Oranları:}

\begin{tabular}{lcc} 
& BraTS 2015 & BraTS 2017 \\
\cline { 2 - 3 } Tüm tümör & $\% 94.01$ & $\% 94.63$ \\
Çekirdek tümör & $\% 94.29$ & $\% 85.6$ \\
Genişlemiş & $\% 87.32$ & $\% 93.54$ \\
tümör & & \\
\hline
\end{tabular}

BraTS-2020

\begin{tabular}{lcc} 
& $\begin{array}{c}\text { Dice Benzerlik } \\
\text { Oranı }\end{array}$ & $\begin{array}{c}\text { Hausdorff } \\
\text { Benzerlik } \\
\text { Oranı }\end{array}$ \\
\cline { 2 - 3 } Tüm tümör & $\% 87.20$ & 6.44 \\
Çekirdek tümör & $\% 81.14$ & 24.36 \\
$\begin{array}{l}\text { Genişlemiş } \\
\text { tümör }\end{array}$ & $\% 78.67$ & 18.95 \\
\hline
\end{tabular}

Derin Vox2 Vox adiverilen 3 boyutlu hacimden 3 Öğrenme, boyutlu hacme beyin tümör segmentasyonu sağlayan, çekişmeli üretici ağ mimarisi sunulmuştur.
Açık kaynaklı bir veri seti: https:// 2021, [31] (Springer) figshare.com/ articles/dataset/brain_tumor_dataset/1512427

Bizim Çalışmamız
BraTS 2020

\footnotetext{
Derin Çok ölçekli bir yaklaşım içeren Derin Öğrenme, Evrişimli Sinir Ağı (DCNN) kullanarak tam otomatik beyin tümörü segmentasyonu CNN ve sinıflandırma modeli sunulmuştur.

U-net mimarisi ile T1 Ce sekansındaki Derin Mr görüntülerinde tümör segmentasyonu Öğrenme, gerçekleştirilmiştir. Normalizasyon olarak CNN Mr görüntülerine kırpma algoritması uygulanmıştır.
}

Dice Benzerlik Oranı: \%82.8

Hassaslik: \%94

Dice Benzerlik Oranı \%86

Hassaslık: $\% 80$

\subsection{Derin öğrenme ile medikal görüntülerde sınıflandırma ve hastalık teşhisi}

Her bir hastanın medikal görüntüleri için uygun bir ayırıcı tanı koyabilmek oldukça önemlidir ve bu sınıflandırma problemi olarak tanımlanabilir. Sınıflandırma görevi bir hastalığın varlığının veya yokluğunun belirlenmesi, tipinin belirlenmesi; 
örneğin bir kanser türünün iyi huylu veya kötü huylu olduğunun belirlemesi gibi geniş kapsamlı bir uygulama alanı içerir. Bu alanda derin öğrenme yöntemlerinden sıklıkça faydalanılır. CNN algoritmaları özellikle bu görev için oldukça kullanışlıdır.

Derin öğrenme kullanılarak medikal görüntülerde sınıflandırma çalışmalarının ilk makaleleri 2013 yılında; Yığınlanmış özdevinimli kodlayıcılar(SAE) ve Kısıtlı Boltzmann Makineleri (RBM) algoritmaları kullanılarak nörogörüntüleme üzerine yayınlanmıştır. Brosch ve Tam (2013) [32], Plis ve diğerleri. (2014) [33], Suk ve Shen (2013)[34] , Suk ve diğerleri (2014)[35] DBN ve SAe algoritmaları ile MR görüntülerinden Alzaymır hastalığının varlığını tanımak üzerine çalışmalar yapmışlardır.

Daha sonraları CNN algoritmaları ile bu alanda yapılan çalışmalar çok daha başarılı sonuçlar vermiş̧ir. Örneğin; Fundus kamerasından elde edilen retina görüntüsünde derin öğrenme çalışmaları gerçekleştirilebilmektedir. Diyabetik retinopati tespiti Gulshan ve diğ. (2016)[36], Gargeya ve diğ. (2017)[37] için CNN algoritmaları kullanılmış ve \%90 aralığında hassasiyet ve özgüllük elde edilmiştir. Benzer bir çalışmada Lam ve diğ, (2018)[38] retinopatinin evrelerini bulmak üzere renkli fundus görüntülerinde çoklu sınıflandırma için CNN algoritması kullanılarak \%95 hassasiyet sunulmuşlardır. Yine fundus kamerası görüntüleri ile glukom (göz tansiyonu) sınıflandırması CNN ile yapılarak, uzman görüşüne oldukça yakın \%94 bir özgüllük elde edilerek Gómez-Valverde ve diğ. (2019) [39] tarafından sunulmuştur.

Bir diğer sınıflandırma problemi medikal görüntüler üzerinden kanser türlerinin sınıflandırılmasıdır. Beyin tümörü türleri için çoklu sınıflandırma çalışmasının bir örneği "Keras" altyapısı kullanılarak Ucuzal ve diğ. (2019) [40] gerçekleştirilmiştir. Waghmare ve diğ. (2021) [41] beyin tümörü sınıflandırma çalışmalarında temel CNN altyapısı ve VGG-16 mimarilerini kullanarak online yayınlanan bir veri setinde \%95 lik bir doğruluk yakalamışlardır. Díaz-Pernas ve diğ. (2021)[31] de CNN mimarisine dayanan tam otomatik beyin segmentasyon ve sınıflandırma çalışmalarında \%97 lik doğrulukla büyük bir başarıya ulaşmışlardır. Meme kanseri tespiti ve sınıflandırması çalışmalarında da derin öğrenme oldukça önemlidir. Nawaz ve diğ, (2018) [42] çalışmalarında yalnızca iyi ve kötü huylu meme kanseri tespitini değil, fibroadenoma, lobular carcinoma gibi alt türleri de tespit etme çalışmaları yaparak \%95 üzerinde doğruluk yakalamışlardır. Khan ve diğ. (2019)[43] çalışmalarında transfer öğrenme ile meme kanserinin tespiti ve sınıflandırılması için birleştirilen üç farklı CNN mimarisi (GoogLeNet, VGGNet ve ResNet) kullanılarak meme sitolojisi görüntülerinden özellikler çıkarmışlardır. Zheng ve diğ. (2020) [44] çalışmalarında; meme tümörü tespiti için MRI, ultrason, dijital meme tomosentezi ve mamografi gibi çeşitli görüntüleme modalitelerinde karakterize etmek için CNN tabanlı transfer öğrenimi gerçekleştiren bir modeli; etkili Adaboost Algoritması (DLA-EABA) ve gelişmiş hesaplama teknikleriyle birleştirerek sunmuşlardır. Bunun sonucunda $\% 97$ lik doğruluk oranı ile etkileyici bir başarıya ulaşmışlardır. Servikal (rahim ağzı) kanseri; (Alyafeai ve Ghouti 2020)[45],(Wu , Yan ve diğ. 2018) [46], (Hussain ve diğ. 2020)[47], Prostat kanseri (Arvidsson ve diğ. 2018 )[48], PET CT ve MR görüntüleri ile Akciğer kanseri; (Sun ve diğ. 2016)[49], (Lakshmanaprabu ve diğ. 2019)[50], (Marjolein ve diğ. 2021)[51] teşhisi ve sınıflandırma çalışmaları yapılmıştır. Derin öğrenme ile hastalık teşhisinde oldukça başarılı sonuçların alındığı bir diğer kanser türü ise cilt kanseridir. Bu konuda Dorj ve diğ. (2018)[52], (Jinnai ve diğ. 2020)[53] genellikle çoklu sınıflandırma uygulamaları yapmıştır ve buna rağmen başarılar oldukça yüksektir. Örneğin; Esteva ve diğ. (2017)[54] herhangi bir önişlem yapmadan doğrudan görüntüleri ve etiketlerini girdi olarak kullanan, yalnızca tek bir CNN ağı ile 2000'den fazla cilt hastalığının sınıflandırılmasını sağlayan bir çalışma yaparak uzman dermatologlar ile karşılaştırılabilir bir yeterlilik düzeyi sunmuştur.

Sınıflandırma için bir diğer alan ise son iki yıldır tüm dünyayı etkisi altına alan Covid-19 hastalığının teşhisidir. COVID-19, Dünya Sağlık Örgütü (World Health Organization-WHO) tarafından, özellikle sağlık sistemi zayıf olan tüm ülkelerde milyonlarca yaşamı etkileme potansiyeli olan bir hastalık olarak ilan edildi. Teşhisinde çoğu zaman test kitleri kullanılmasının yanı sıra akciğer görüntüsüne de ihtiyaç duyulmaktadır. Bu alanda da çalışmalar yayınlanmış, genellikle akciğer röntgeni, ultrason veya tomografi görüntüleri kullanılarak derin öğrenme algoritmaları ile hastalığın varlığı sorgulanmıştır. Wang ve diğ. (2020)[55] Covid-19 ve tipik pnomoniyi ayırt etmek için BT görüntülerinde ilgili alanları çizerek (ROI-region of interest) bunu CNN modelinde eğitmişlerdir. Roy ve diğ. (2020) [56] ise ultrason video görüntüleri üzerinde hastalığın varlığını teşhis ederek farklı bir yol üzerinden ilerlemişlerdir. Hemdan ve diğg. (2020) [57] çalışmalarında, COVID-19’u 7 farklı derin öğrenme sınıflandırıcısına dayalı 2 boyutlu X-ray görüntülerinde otomatik olarak tanımlamak veya onaylamak için yeni bir COVIDXNet çerçevesi önermiş̧ir. Bu algoritmalar VGG19, DenseNet121, ResNetV2, InceptionV3, InceptionResNetV2, Xception ve MobileNetV2 dir. 


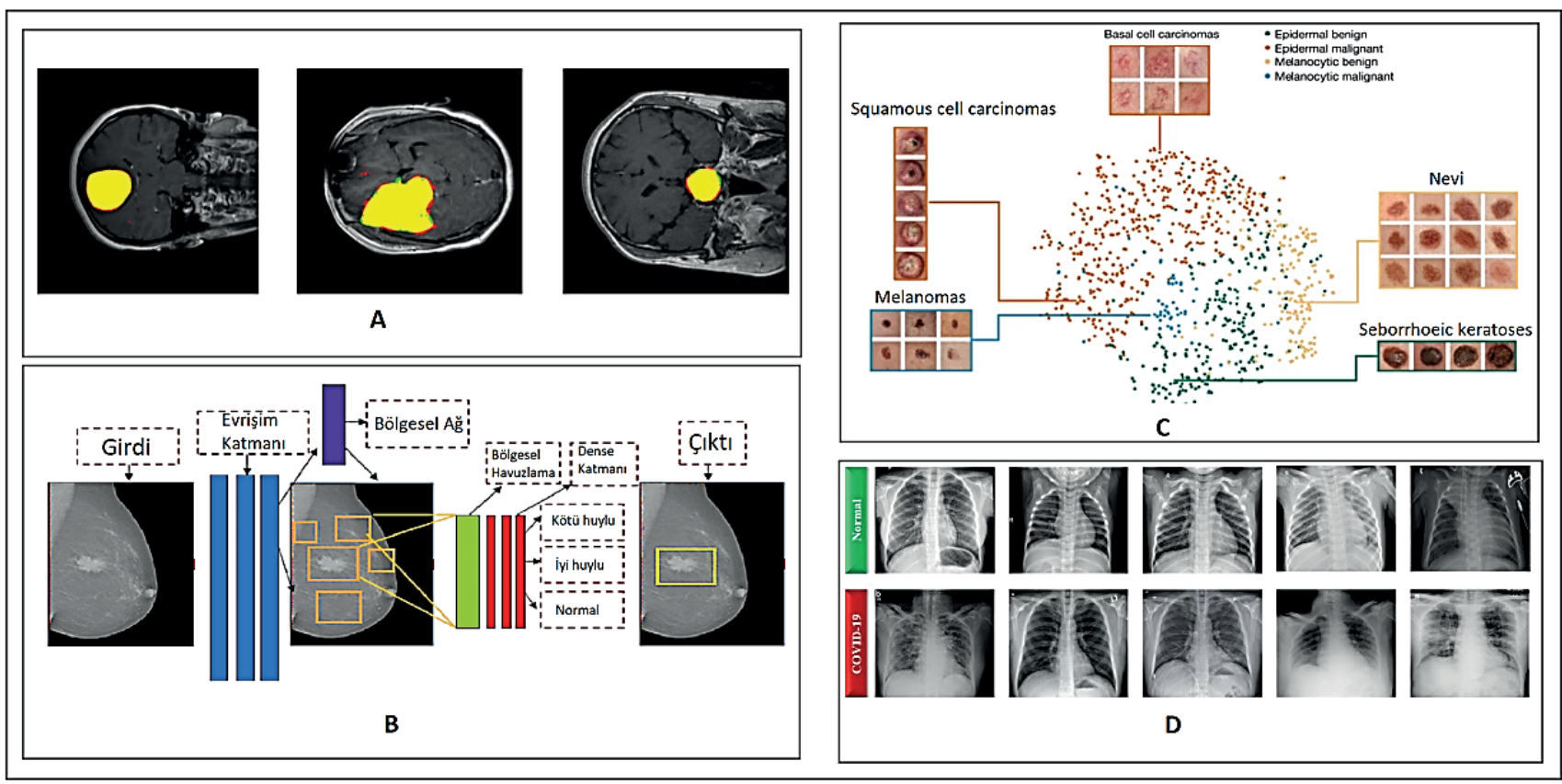

Şekil 5. Derin Öğrenme ile Medikal Görüntülerin Sınıflandırılması

Şekil 5'te sınıflandırma çalışmaları sunulmuştur. A- Beyin tümörü sınıflandırması çalışmasıdır. Görüntülerdeki tümörler sırayla meningioma, glioma, ve pituitary tümörüdür (Díaz-Pernas ve diğ. 2021). B- Memede tümörün varlı̆̆ının tespiti ve tümörün iyi ya da kötü huylu olarak sınıflandırılması çalışmasıdır (Zheng ve diğ. 2020). C- Fotoğraflar üzerinden cilt kanseri türlerinin sınıflandırılmasıdır (Esteva ve diğ. 2017). D-Covid-19 hastalı̆̆ının akciğer görüntülerinden otomatik olarak tespit edilmesi çalışmasıdır. Burada üst sıradaki görüntüler normal akciğere ait röntgen görüntüsü, alt sıradaki görüntüler ise Covid-19 ile enfekte olmuş hastalara ait röntgen görüntüleridir (Hemdan ve diğ. 2020). 
Tablo 2

Medikal görüntülerden derin ögrrenme ile otomatik Covid-19 hastalı̆̆ının tespit edilmesi konusunda araştırmacılar tarafindan kullanılan farklı teknikler ve başarı oranlarl gösterilmektedir.

\begin{tabular}{|c|c|c|c|c|c|}
\hline Referans & Veri Seti & Modalite & Teknik & Model & $\begin{array}{l}\text { Başarı Değer- } \\
\text { leri }\end{array}$ \\
\hline $\begin{array}{l}\text { Wang ve diğ. [55] } \\
((2021\end{array}$ & $\begin{array}{l}\text { COVID-19, } 55 \text { tipik virus ile enfekte } 44 \\
\text { hastadan oluşan klinik veri seti }\end{array}$ & BT görüntüleri & $\begin{array}{l}\text {,Derin öğrenme } \\
\text { ROI }\end{array}$ & CNN, Karar ağaçları & $\begin{array}{c}\text { Doğruluk=82.9 } \\
\text { Hassaslık=81 } \\
\text { Özgüllük }=84 \\
\text { F1-Score }=77\end{array}$ \\
\hline $\begin{array}{l}\text { Hemdan ve diğ. [57] } \\
((2020\end{array}$ & $\begin{array}{l}\text { (hasta görüntüsü (Açık kaynak } 181 \\
\text { https://github.com/ieee8023/ } \\
\text { covid-chestxray-dataset }\end{array}$ & X-ray & $\begin{array}{l}\text { Derin Öğrenme } \\
\text { CNN }\end{array}$ & $\begin{array}{l}\text { COVIDX-Net, (VGG19, } \\
\text { (DenseNet201 }\end{array}$ & $\begin{array}{l}\text { Doğruluk=90 } \\
\text { Kesinlik=83 } \\
\text { F1-Score }=91\end{array}$ \\
\hline $\begin{array}{l}\text { Saiz ve Barandiaran, } \\
([58](2020\end{array}$ & $\begin{array}{l}\text { (görüntü-(Açık kaynak } 1500 \\
\text { https://www.kaggle.com/c/rsna-pneu- } \\
\text { monia-detection-challenge/data }\end{array}$ & X-ray & $\begin{array}{l}\text {,Derin Öğrenme } \\
\text { CNN ve transfer } \\
\text { öğrenme }\end{array}$ & VGG-16 SDD & $\begin{array}{c}\text { Doğruluk }=94.92 \\
\text { Hassaslik }=94.92 \\
\text { Kesinlik }=92 \\
\text { F1-Score }=97\end{array}$ \\
\hline $\begin{array}{l}\text { Farooq ve Hafeez } \\
([59] \quad(2020\end{array}$ & $\begin{array}{l}\text { COVIDx: } 45 \text { COVID-19, } 1203 \text { Normal, } \\
931 \text { Bacterial Pneumonia, } 660 \text { Viral } \\
\text { Pneumonia Hasta }\end{array}$ & X-ray & $\begin{array}{l}\text {,Derin Öğrenme } \\
\text { CNN }\end{array}$ & $\begin{array}{l}\text { COVID-ResNet (Res- } \\
\text { (Net-50 }\end{array}$ & $\begin{array}{c}\text { Doğruluk }=96.23 \\
\text { Hassaslik }=100 \\
\text { Kesinlik }=100 \\
\text { F1-Score }=100\end{array}$ \\
\hline $\begin{array}{l}\text { Vaid ve diğ. [60] } \\
((2020\end{array}$ & $\begin{array}{l}\text { (hasta görüntüsü (Açık kaynak } 181 \\
\text { https://github.com/ieee8023/ } \\
\text { covid-chestxray-dataset }\end{array}$ & X-ray & $\begin{array}{l}\text {,Derin Öğrenme } \\
\text { CNN }\end{array}$ & VGG-19 & Doğruluk=96.3 \\
\hline $\begin{array}{l}\text { Wang ve Wong [61] } \\
((2020\end{array}$ & $\begin{array}{l}\text { COVIDx: } 266 \text { COVID-19, } 8066 \text { Nor- } \\
\text { mal, 5,538 Non-COVID19 Pneumonia } \\
\text { Hasta }\end{array}$ & X-ray & $\begin{array}{l}\text {,Derin Öğrenme } \\
\text { DCNN }\end{array}$ & COVID-Net & $\begin{array}{c}\text { Doğruluk=93.3 } \\
\text { Hassasl1k=91 } \\
\text { PPV }=98.9\end{array}$ \\
\hline $\begin{array}{l}\text { Yang ve diğ. [62] } \\
((2020\end{array}$ & $\begin{array}{l}\text { hastanın BT görüntüsü(146- CO- } 295 \\
\text { (VID 19, } 149 \text { Normal }\end{array}$ & BT görüntüleri & Derin Öğrenme & DenseNet & $\begin{array}{l}\text { Doğruluk }=92 \\
\text { Hassaslik }=97 \\
\text { Özgüllük }=0.8\end{array}$ \\
\hline $\begin{array}{l}\text { Rajaraman ve Anta- } \\
\text { [ni }(2020)[63\end{array}$ & $\begin{array}{l}\text { NIH, CheXpert gibi veri setlerinden } \\
\text { oluşan karma bir veri seti }\end{array}$ & X-ray & $\begin{array}{l}\text { Derin Öğren- } \\
\text { me,,CNN }\end{array}$ & $\begin{array}{c}\text { VGG16 } \\
\text { Segmentasyon }=\text { U-net }\end{array}$ & Doğruluk=99.26 \\
\hline
\end{tabular}

\subsection{Derin öğrenme ile medikal görüntü oluşturma ve dönüştürme}

Medikal alanda; veri tamamlama ve desen keşfinden derin mimariler kullanan çeşitli görüntü oluşturma ve iyileştirme yöntemleri vardır. Bu yöntemler sayesinde veri eksikliğinde veriler arasında dönüşüm sağlanarak, verinin yetersiz olduğu durumlarda veri üreterek algoritmanın daha doğru çalışması sağlanabilir.

Görüntü dönüştürmede, bir giriş görüntüsünü diğerine dönüştürmek için 2D veya 3D CNN'ler kullanılır. Tipik olarak, bu mimariler sınıflandırma ağlarında bulunan havuzlama katmanlarından yoksundur. Bu sistemler daha sonra, üretilen ve istenen çıktı arasındaki farkları kayıp fonksiyonu olarak tanımlayan hem girişin hem de istenen çıktının mevcut olduğu bir veri seti ile eğitilirler [64].

Örneğin çok modaliteli beyin görüntü verilerini birleştirmek hastalık tanımada performansı oldukça arttırır. Ancak bunu yapmak oldukça zordur çünkü eksik verilerin bulunması bu görevi oldukça zorlu kılar. Bu eksik verileri tamamlamak için farklı modalitelerden dönüşüm sağlamak bir çözümdür. Qu, Zhang ve diğ. (2020) [65] 3T MR dan 7T beyin MR, Li ve diğ. (2014) [66] MR dan PETgörüntüsü oluşturarak, bu görüntülerin orijinal veriler eksik olduğunda veya elde edilmediğinde Alzheimer hastalığ için bilgisayar destekli tanı sistemlerinde kullanılabileceğini göstermiştir. Yine farklı alanlarda Nie ve diğ. (2018)[67] Derin evrişimli çekişmeli ağ kullanarak MR görüntülerinden BT görüntülerine ve 3T MR dan 7T MR görüntülerine dönüşüm sağlamışlardır.

Medikal sentetik görüntüler üretmek, bilgisayar destekli tanıda ve doktor eğitiminde veri arttırmayı sağlayarak teşhis güvenilirliğini arttırmaya yardımcı olur. Bu amaçla Han ve diğ. (2018) [68] beyin MR görüntülerinden GAN kullanarak sentetik MR görüntüleri elde etmişlerdir ve uzman bir doktorun bile görselleri ayırt etmekte zorlandığını belirtmişlerdir. Qiao ve diğ. (2020) [69] bağlam duyarlı tekrarlayan üretken çekişmeli ağ ile (CorGAN) 3 boyutlu Mr görüntüsü üretmişlerdir. 
Şekil 6’te sentetik görüntü üretme çalışmalarından örnekler gösterilmiştir. A: Göz damar ağlarından retinal görüntü sentezlenmiştir. Bu çalışmada CycleGAN kullanılmıştır [70]. B: pix2pix GAN modeli ile Mr görüntülerinden Pet görüntülerine dönüşüm gerçekleştirilmiştir [71]. C: DCGAN ile T1 ve T2 sekanslarında sentetik beyin MR görüntüleri üretilmiştir [68].

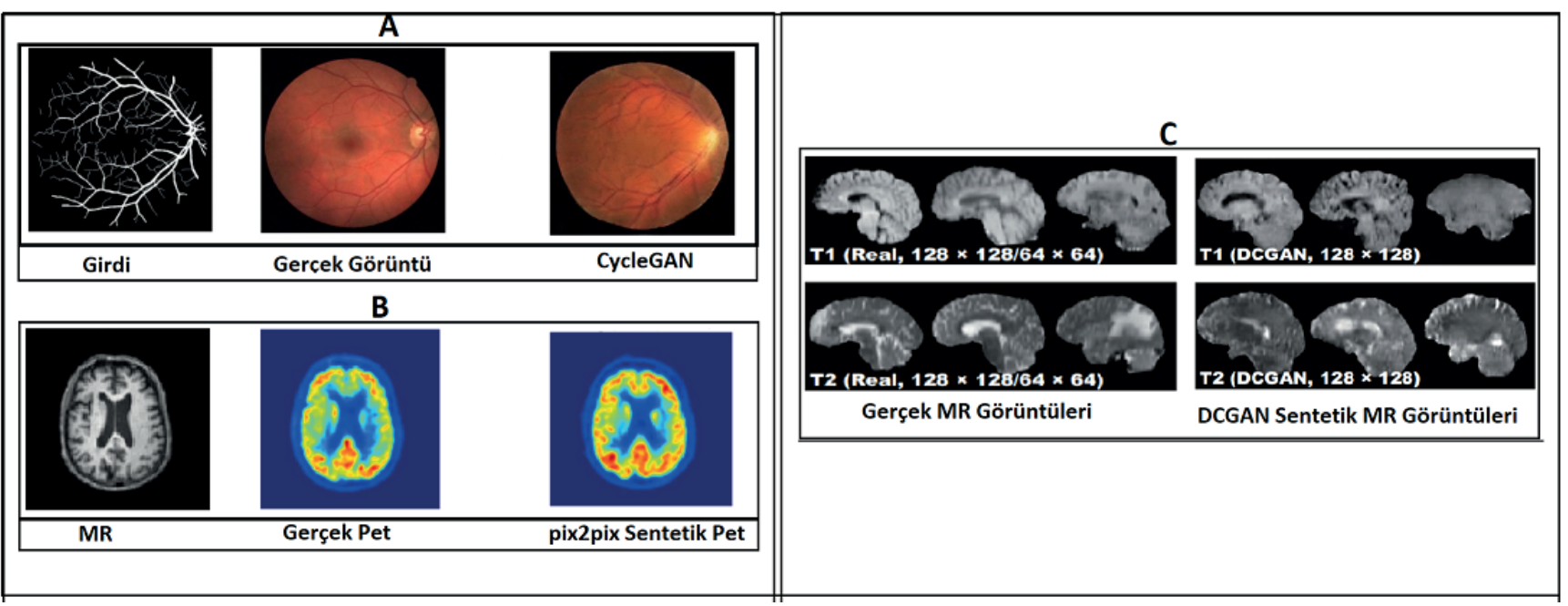

Şekil 6. Derin öğrenme ile medikal görüntü oluşturma

\subsection{Derin öğrenme ile medikal görüntülerde iyileştirme}

Yüksek kaliteli görüntüler doktorlar ve bilgisayar destekli teşhis sistemleri (CAD) için daha doğru ve etkili bilgi referansı sunmayı sağlarlar. Ancak kimi zaman; bu görüntülerin elde edilmesi sırasında yaşanan bazı sorunlar, hızlı davranılması gerekliliği, donanımsal yetersizlikler yüksek kalitede görüntü elde edilmesinin önüne geçer. Görüntü iyileştirme; dijital görüntülerin (örn; süper çözünürlük, gürültü azaltma, bulanıklaştırma, kontrast iyileştirme gibi işlemler ile) görüntüleme, sınıflandırma, algılama ve segmentasyon gibi daha ileri görüntü analizi için daha uygun olması için ayarlama işlemidir.

Armanious ve diğ. (2020) [72], MedGAN adında uçtan uca medikal görüntü çevirisi sağlayan bir çerçeve geliştirmişlerdir. PET-BT dönüşümü, MR görüntüsündeki hareketlilikleri düzeltme ve PET görüntülerini netleştirme (gürültü arındırma) görevleri için kullanılmıştır. Tıbbi görüntülerde gürültü olması, zamanında teşhis, analiz ve tedavi sürecini zorlaştıran doğrudan veya dolaylı bir etki bırakır. Jifara ve diğ. (2018) [73]; MR, ultrason, mamografi gibi görüntüleme tekniklerinde gürültüyü azaltmak için otomatik tamamlayıcı(autoencoder) yanısıra kalıntı öğrenme ve batch normalleştirme yöntemlerini de kullanarak küçük boyutlu veri setlerinde dahi başarılı olmuşlardır.

Yamashita ve Markov (2020) [74] Optik Koherens Tomografi (OCT) ile elde edilen düşük kalitede optik sinir başı görüntülerini süper ç̧̈zünürlük yöntemi ile yüksek kalitede görüntü haline getirmişlerdir. Bunun için de Süper çözünürlüklü evrişimli sinir ağı (SRCNN), Çok derin evrişimli ağ (VDSR), Derin özyinelemeli evrişimli ağ (DRCN) ve gelişmiş süper çözünürlüklü üretken karşı ağ (ESRGAN) gibi mimarileri denemişlerdir. Raudonis ve diğ. (2021) [75] mikroskobik görüntüde embriyo büyütme için gerekli spektral bilgiyi kaybetmeden veri miktarını 7 kata kadar azaltmayı sağlayan, U-Net mimarisine dayalı çok odaklı görüntü füzyon yaklaşımını önermişlerdir. Li M. Ve diğ. (2018) [76]; BT görüntülerinde her dilimin düşük çözünürlüğünü 3D CNN ile yüksek çözünürlüklü hale getirmişlerdir. 


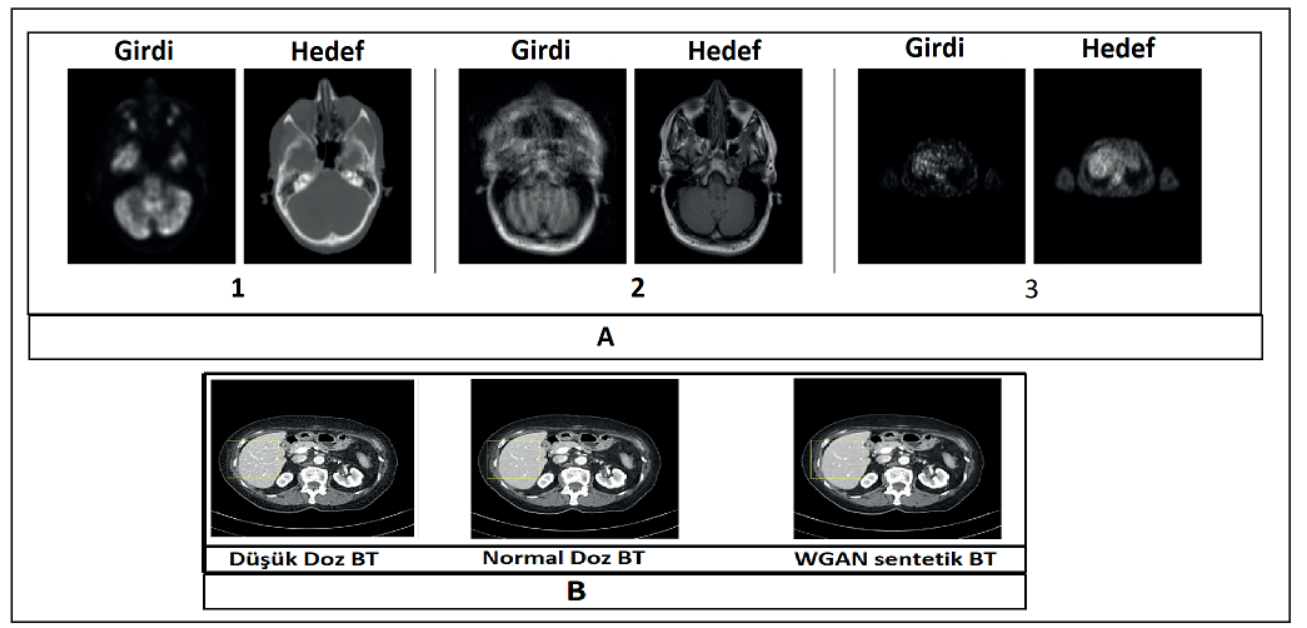

Şekil 7. Derin öğrenme ile medikal görüntü oluşturma ve iyileştirme

Şekil 7'de derin öğrenme ile medikal görüntülerin dönüşümleri ve iyileştirilmelerinden örnekler sunulmuştur. 1. çalışma MedGAN adlı çalışmadır [72]. 6-A-1: PET görüntüsünden BT görüntüsüne dönüşüm sağlanmıştır. 6-A-2: Mr görüntüsündeki hareketlilikten kaynaklı bozukluğu iyileştirme gerçekleştirilmiştir. 6-A-3: PET görüntüsündeki gürültüyü azaltarak görüntüde iyileştirme sağlanmıştır. 2. çalışmada [77] Düşük doz radyasyon kullanılarak çekilen tomografi görüntülerindeki gürültü WGAN ile giderilerek görüntü üzerinde iyileştirme yapılarak normal dozda radyasyon ile çekilen tomografi görüntüsüne dönüştürülmüştür.

\subsection{Derin Öğrenme Uygulamalarında Kullanılan Medikal Görüntü Veri Setleri}

Derin öğrenme algoritmalarının başarılı bir biçimde eğitilebilmesi ve sonuç üretebilmesi için gereken en önemli etken olabildiğince çok sayıda veri içeren, etiketlemeleri doğru bir biçimde yapılmış ve düzgün bir biçimde oluşturulmuş veri kümesidir. Derin öğrenme ile medikal görüntü işlemek için çeşitli alanlarda, sıklıkla kullanılan, otoritelerce kabul görmüş bazı büyük veri kümeleri bulunmaktadır.

- The NIH Kliniği Göğüs Röntgen Veri Seti (The National Institutes of Health Chest X-rays dataset) : 30.805 hastadan 112.120 ön göğüs röntgeni içermektedir. Bu röntgen görüntülerinde, ilgili radyolojik raporlardan çıkarılan 14 yaygın göğüs hastalığı metin madenciliği kullanılarak oluşturulan etiketler ile etiketlenmiştir. Etiketler doğal dil işleme ile elde edildiği için bazı hatalar içerebilmektedir. Hastaların izni ile çekilen ve yapay zekâ tanılarını iyileştirmek için kullanılan bu veri seti ücretsizdir ve akademik olarak kullanıma açıktır [78].

- Kanser Görüntüleme Arşivi (The Cancer Imaging Archive- TCIA): Ulusal Kanser Enstitüsü’nün (NCI) resmi bir dijital görüntü deposudur ve kanserle ilgili veri kümelerini paylaşmak için oluşturulmuştur [79]. Platformda veriler için uygun kimlik gizleme yöntemleri uygulanarak yasal ve teknik prosedürler düzenlenmiştir. TCIA; görüntüleme (MR, BT, PET vb.), klinik, genomik ve yirmiden fazla tümör türüyle (akciğer, beyin, göğüs vs.) ilgili diğer verileri içeren açık erişimli bir portaldır.

- BraTS Veri Seti: 2012 yılından bu yana Uluslararası Tıbbi Görüntü Hesaplama ve Bilgisayar Destekli Müdahale Konferansı (MICCAI) kapsamında düzenlenen Beyin Tümörü Segmentasyonu (BraTS) yarışması için oluşturulan veri setidir [80-81]. Veri setinde T1-T1ce-T2-Flair sekanslarında MR görüntüleri ve uzmanlar tarafından etiketlenerek segmente edilmiş tümörler bulunmaktadır. Yarışmanın amacı MR görüntülerinde beyin tümörünü (ödem, nekroz tümör, tüm tümör) segmentlere ayırmak için en iyi algoritmayı belirlemeyi amaçlamaktır. 2018 yılından itibaren, genel hasta sağ kalımını tahmin etmek gibi klinik olarak ilgili görevlere de odaklanılmıştır.

- COVID-CTve SARS-CoV-2 CT-tarama veri setleri: Covid 19 hastalığında erken teşhis ve tedaviye yardımcı olmak amacıyla Bt görüntülerinden otomatik hastalık tespiti ile ilgili çalışmalar yapılmaktadır. Bunun için iki 
güncel veri seti bulunmaktadır. COVID-CT [82]; farklı kliniklerin bilimsel araştırmalarda kullandığı ve araştırmalarda kullanılması amacıyla bağışladığı, Covid-19 hastalık teşhisine sahip 216 hastadan alınan 349 BT görüntüsünden oluşan bir veri setidir. SARS-CoV-2 CT-tarama [83] ise Brezilya São Paulo hastanelerinden toplanan, Covid-19 ile enfekte olmuş 60 hastanın 1252 BT görüntüsünden ve Covid-19 ile enfekte olmamış ancak farklı akciğer hastalıklarına sahip 60 hastanın 1230 BT görüntüsünden oluşan bir veri setidir.

\section{- Mamografi Taraması için Dijital Veritabanı (DDSM: Digital Database for Screening Mammography):} 2620'den fazla hasta verisi içeren, meme kanserinin otomatik olarak tanınmasını sağlayan uygulamalarda kullanılan, oldukça büyük bir mamografi veri setidir [84]. Her taramada 2 memenin de 2 CC (kraniyokaudal görünüm) ve MLO (mediolateral oblik görünüm) olmak üzere toplamda 10480 mamogram verisi bulunmaktadır. Veri seti normal, iyi huylu ve melonom olarak üç kategoride etiketlenmiştir ve tanısal görüntüleme doktoru tarafından kontrol edilerek doğrulanmıştır. DDSM veri seti JPEG formatında görüntü bulundurmaktadır.

\section{TARTIŞMA VE SONUÇ}

Derin öğrenme medikal görüntüleme analizinde kullanılan en popüler yöntemlerdendir. Farklı ağ mimarilerine sahip algoritmaları olan derin öğrenmenin, sağlık alanında, özellikle medikal görüntülerde kullanımı oldukça yaygındır. Hastalıkların erken teşhisi, erken tedavisi, uzmanların yoğunluğunu azaltma, farklı uzman görüşleri gibi alanlarda bu yöntemlerden sıklıkla yararlanılmaktadır. Yeterli sayıda veriye erişememe, matematiksel modellerin iyi kurgulanmaması gibi problemler derin öğrenme modelleri için hala var olan problemler olsa da literatürde \%90'ın üzerinde başarı değerlendirmesine sahip pek çok çalışmanın bulunuyor olması, derin öğrenme algoritmalarının bu alanda ne kadar büyük bir gelecek vaat ettiğini göstermektedir.

Bu çalışmada derin öğrenme yöntemlerinin medikal görüntüler üzerinde kullanımı incelenmiştir. Segmentasyon, sınıflandırma, hastalık teşhisi, görüntü oluşturma ve iyileştirme alanlarında derin öğrenme ile yapılan çalışmalardan oldukça güncel örnekler sunularak derin öğrenmenin medikal görüntülerde uygulanabilirliği anlatılmıştır. Özellikle MR ve BT gibi medikal görüntülerden, otomatik tümör veya kanser tespit çalışmaları ve medikal görüntülerin kalitesini arttırmaya yönelik çalışmaların oldukça popüler olduğu gözlemlenmiştir. Çalışmada bir de segmentasyon için sıklıkla kullanılan U-net modeli ile BraTS 2020 veri seti kullanılarak beyin tümör segmentasyonu gerçekleştirilmiştir. Eğitim sonunda dice benzerlik oranı \% 86, hassasiyet ise \%80 olarak gözlenmiştir. Ayrıca çalışmalarda sık kullanılan yöntemler ve veri setleri ile derin öğrenme algoritmaları da açıklanmıştır. Tüm bunların, medikal görüntüler ile yapılacak yeni ve farklı çalışmalara derin öğrenme yöntemleri ile yaklaşmak için örnek olması ve yol göstermesi amaçlanmıştır. Çalışmanın amaçlarından biri de medikal görüntüler üzerinde derin öğrenmenin kullanımı ile ilgili güncel Türkçe bir kaynak oluşturmaktır.

\section{Hakem Değerlendirmesi: Dış bağımsız.}

Çıkar Çatışması: Yazarlar çıkar çatışması bildirmemiştir.

Yazar Katkıları: Çalışma Konsepti/Tasarım-N.D., A.G.E.; Veri Toplama- A.G.E.; Veri Analizi/Yorumlama- N.D., A.G.E.; Yazı Taslağı-A.G.E.; İçeriğin Eleştirel İncelemesi-N.D.; Son Onay ve Sorumluluk- N.D., A.G.E.

Finansal Destek: Yazarlar bu çalışma için finansal destek almadığını beyan etmiştir.

\section{Kaynaklar/References}

Kaya, U.,Yılmaz, A.\& Dikmen, Y. (2019). Sağlık Alanında Kullanılan Derin Öğrenme Yöntemleri.Avrupa Bilim ve Teknoloji Dergisi, (16), 792-808.

Krizhevsky A, Sutskever I, Hinton GE. ImageNet classification with deep convolutional neural networks. In: Pereira F, Burges CJC, Bottou L,Weinberger KQ, editors. Advances in neural information processing systems 25. Curran Associates, Inc.; 2012. p. $1097-105$.

Tan, Ziya. Derin öğrenme yardımıyla araç sınıflandırma. MS thesis. Fırat Üniversitesi, Fen Bilimleri Enstitüsü, 2019.

Pervan, N. (2019). Derin öğrenme yaklaşımları kullanarak Türkçe metinlerden anlamsal çıkarım yapma. Yüksek Lisans Tezi, Ankara Üniversitesi Fen Bilimleri Enstitüsü, Ankara. 
Üzen, H., Hanbay, K., Yaya Özellik Tanımak İçin Lm Filtre Temelli Derin Evrişimsel Sinir Ağı, Politeknik Dergisi, *(*): *, (*).

Goodfellow, Ian J., et al. "Generative adversarial networks." arXiv preprint arXiv:1406.2661 (2014).

Chu, Casey, Andrey Zhmoginov, and Mark Sandler. “Cyclegan, a master of steganography.” arXiv preprint arXiv:1712.02950 (2017).

Radford, Alec, Luke Metz, and Soumith Chintala. "Unsupervised representation learning with deep convolutional generative adversarial networks." arXiv preprint arXiv:1511.06434 (2015).

Isola P, Zhu J-Y, Zhou T, Efros AA (2017) Image-to-image translation with conditional adversarial networks. ArXiv preprin

Xia, Xianjun, et al. "Auxiliary classifier generative adversarial network with soft labels in imbalanced acoustic event detection." IEEE Transactions on Multimedia 21.6 (2018): 1359-1371.

Weng, Yu, et al. "NAS-Unet: Neural architecture search for medical image segmentation.” IEEE Access 7 (2019): 44247-44257.

Zheng, Yefeng, et al. "Deep learning based automatic segmentation of pathological kidney in CT: local versus global image context." Deep learning and convolutional neural networks for medical image computing. Springer, Cham, 2017. 241-255.

Pan, Xipeng, et al. "Cell detection in pathology and microscopy images with multi-scale fully convolutional neural networks." World Wide Web 21.6 (2018): 1721-1743.

Farag, Amal, et al. "Automatic pancreas segmentation using coarse-to-fine Superpixel labeling." Deep learning and convolutional neural networks for medical image computing. Springer, Cham, 2017. 279-302.

Long, J., Shelhamer, E., Darrell, T.: Fully convolutional networks for semantic segmentation. In: CVPR. (2015)

Nie, Dong, et al. "Fully convolutional networks for multi-modality isointense infant brain image segmentation." 2016 IEEE 13 Th international symposium on biomedical imaging (ISBI). IEEE, 2016.

Zhou X, Takayama R, Wang S, Hara T, Fujita H. Deep learning of the sectional appearances of 3D CT images for anatomical structure segmentation based on an FCN voting method. Med Phys. 2017;44(10):5221-5233. doi: 10.1002/mp.12480. [PubMed] [CrossRef] [Google Scholar]

Sun, Jindong, et al. "Segmentation of the multimodal brain tumor image used the multi-pathway architecture method based on 3D FCN." Neurocomputing 423 (2021): 34-45.

Ronneberger, Olaf, Philipp Fischer, and Thomas Brox. "U-net: Convolutional networks for biomedical image segmentation." International Conference on Medical image computing and computer-assisted intervention. Springer, Cham, 2015.

Çiçek, Özgün, et al. "3D U-Net: learning dense volumetric segmentation from sparse annotation.” International conference on medical image computing and computer-assisted intervention. Springer, Cham, 2016.

Zhou, Zongwei, et al. "Unet++: A nested u-net architecture for medical image segmentation." Deep learning in medical image analysis and multimodal learning for clinical decision support. Springer, Cham, 2018. 3-11.

Alom, Md Zahangir, et al. "Recurrent residual convolutional neural network based on u-net (r2u-net) for medical image segmentation." arXiv preprint arXiv:1802.06955 (2018).

Ibtehaz, Nabil, and M. Sohel Rahman. "MultiResUNet: Rethinking the U-Net architecture for multimodal biomedical image segmentation.” Neural Networks 121 (2020): 74-87.

Sun, Jesse, et al. "SAUNet: shape attentive U-Net for interpretable medical image segmentation." International Conference on Medical Image Computing and Computer-Assisted Intervention. Springer, Cham, 2020.

Tong, Xiaozhong, et al. "ASCU-Net: Attention Gate, Spatial and Channel Attention U-Net for Skin Lesion Segmentation.” Diagnostics 11.3 (2021): 501.

Li, Chen, et al. "MRFU-Net: A Multiple Receptive Field U-Net for Environmental Microorganism Image Segmentation.” Information Technology in Biomedicine. Springer, Cham, 2021. 27-40.

Abd El Kader Isselmou, Guizhi Xu, Shuai Zhang, Sani Saminu, and Imran Javaid, "Deep Learning Algorithm for Brain Tumor Detection and Analysis Using MR Brain Images," in Proceedings of the 2019 International Conference on Intelligent Medicine and Health, ACM, 2019.

$\mathrm{Hu}$, Kai, et al. "Brain tumor segmentation using multi-cascaded convolutional neural networks and conditional random field." IEEE Access 7 (2019): 92615-92629

Nema, Shubhangi, et al. "RescueNet: An unpaired GAN for brain tumor segmentation.” Biomedical Signal Processing and Control 55 (2020): 101641.

Wang, Cirillo, M. D., Abramian, D., \& Eklund, A. (2020). Vox2Vox: 3D-GAN for brain tumour segmentation. arXiv preprint arXiv:2003.13653. Shuai, et al. "A deep learning algorithm using CT images to screen for Corona Virus Disease (COVID-19)." European Radiology (2021): 1-9.

Díaz-Pernas, Francisco Javier, et al. "A Deep Learning Approach for Brain Tumor Classification and Segmentation Using a Multiscale Convolutional Neural Network." Healthcare. Vol. 9. No. 2. Multidisciplinary Digital Publishing Institute, 2021.

Brosch, Tom, Roger Tam, and Alzheimer's Disease Neuroimaging Initiative. "Manifold learning of brain MRIs by deep learning." International Conference on Medical Image Computing and Computer-Assisted Intervention. Springer, Berlin, Heidelberg, 2013.

Plis, S. M., Hjelm, D. R., Salakhutdinov, R., Allen, E. A., Bockholt, H. J., Long, J. D., et al. (2014). Deep learning for neuroimaging: a validation study. Front. Neurosci. 8:229. doi: 10.3389/fnins.2014.00229

Suk, H.-I., and Shen, D. (2013). "Deep learning-based feature representation for AD/MCI classification," in International Conference on Medical Image Computing and Computer-Assisted Intervention, Vol 16 (Nagoya), 583-590.

Suk, H.-I., Lee, S.-W., Shen, D., and Alzheimer's Disease Neuroimaging Initiative. (2014). Hierarchical feature representation and multimodal fusion with deep learning for AD/MCI diagnosis. NeuroImage 101, 569-582. doi: 10.1016/j.neuroimage.2014.06.077

Gulshan, Varun, et al. "Development and validation of a deep learning algorithm for detection of diabetic retinopathy in retinal fundus photographs." Jama 316.22 (2016): 2402-2410

Gargeya, Rishab, and Theodore Leng. “Automated identification of diabetic retinopathy using deep learning.” Ophthalmology 124.7 (2017): $962-969$.

Lam, Carson, et al. "Automated detection of diabetic retinopathy using deep learning." AMIA summits on translational science proceedings 2018 (2018): 147.

Gómez-Valverde JJ, Antón A, Fatti G, et al. Automatic glaucoma classification using color fundus images based on convolutional neural networks and transfer learning. Biomed Opt Express. 2019;10(2):892-913. Published 2019 Jan 25. doi:10.1364/BOE.10.000892 
Ucuzal, Hasan, Şeyma YAŞAR, and Cemil Çolak. "Classification of brain tumor types by deep learning with convolutional neural network on magnetic resonance images using a developed web-based interface.” 2019 3rd International Symposium on Multidisciplinary Studies and Innovative Technologies (ISMSIT). IEEE, 2019

Waghmare, Vishal K., and Maheshkumar H. Kolekar. "Brain Tumor Classification Using Deep Learning.” Internet of Things for Healthcare Technologies. Springer, Singapore, 2021. 155-175.

Nawaz, Majid, Adel A. Sewissy, and Taysir Hassan A. Soliman. "Multi-class breast cancer classification using deep learning convolutional neural network.” Int. J. Adv. Comput. Sci. Appl 9.6 (2018): 316-332.

Khan, SanaUllah, et al. "A novel deep learning based framework for the detection and classification of breast cancer using transfer learning." Pattern Recognition Letters 125 (2019): 1-6.

Zheng, Jing, et al. "Deep learning assisted efficient AdaBoost algorithm for breast cancer detection and early diagnosis.” IEEE Access 8 (2020): 96946-96954.

Alyafeai, Zaid, and Lahouari Ghouti. “A fully-automated deep learning pipeline for cervical cancer classification.” Expert Systems with Applications 141 (2020): 112951.

Wu, Miao, et al. "Automatic classification of cervical cancer from cytological images by using convolutional neural network.” Bioscience reports 38.6 (2018).

Hussain, Elima, et al. "A comprehensive study on the multi-class cervical cancer diagnostic prediction on pap smear images using a fusion-based decision from ensemble deep convolutional neural network.” Tissue and Cell 65 (2020): 101347.

Arvidsson, Ida, et al. “Generalization of prostate cancer classification for multiple sites using deep learning.” 2018 IEEE 15 th International Symposium on Biomedical Imaging (ISBI 2018). IEEE, 2018.

Sun, Wenqing, Bin Zheng, and Wei Qian. “Computer aided lung cancer diagnosis with deep learning algorithms.” Medical imaging 2016: computer-aided diagnosis. Vol. 9785. International Society for Optics and Photonics, 2016.

Lakshmanaprabu, S. K., et al. “Optimal deep learning model for classification of lung cancer on CT images.” Future Generation Computer Systems 92 (2019): 374-382.

Heuvelmans, Marjolein A., et al. "Lung cancer prediction by Deep Learning to identify benign lung nodules.” Lung Cancer 154 (2021): 1-4.

Dorj, Ulzii-Orshikh, et al. “The skin cancer classification using deep convolutional neural network.” Multimedia Tools and Applications 77.8 (2018): 9909-9924.

Jinnai, Shunichi, et al. “The development of a skin cancer classification system for pigmented skin lesions using deep learning.” Biomolecules 10.8 (2020): 1123.

Esteva, Andre, et al. "Dermatologist-level classification of skin cancer with deep neural networks.” nature 542.7639 (2017): 115-118.

Wang, Shuai, et al. “A deep learning algorithm using CT images to screen for Corona Virus Disease (COVID-19).” European radiology (2021): 1-9.

Roy, Subhankar, et al. "Deep learning for classification and localization of COVID-19 markers in point-of-care lung ultrasound." IEEE Transactions on Medical Imaging 39.8 (2020): 2676-2687.

Hemdan, Ezz El-Din, Marwa A. Shouman, and Mohamed Esmail Karar. "Covidx-net: A framework of deep learning classifiers to diagnose covid-19 in X-ray images.” arXiv preprint arXiv:2003.11055 (2020).

F. A. Saiz and I. Barandiaran, “COVID-19 detection in chest X-ray images using a deep learning approach,” International Journal of Interactive Multimedia and Artificial Intelligence, vol. 6, p. 1. In press, 2020.

M. Farooq and A. Hafeez, “Covid-resnet: A deep learning framework for screening of covid19 from radiographs,” arXiv preprint arXiv:2003.14395, 2020.

S. Vaid, R. Kalantar, and M. Bhandari, “Deep learning COVID-19 detection bias: accuracy through artificial intelligence,” International Orthopaedics, vol. 44, 2020

L. Wang and A. Wong, "Covid-net: A tailored deep convolutional neural network design for detection of covid-19 cases from chest X-ray images," arXiv preprint arXiv:2003.09871, 2020.

S. Yang, L. Jiang, Z. Cao et al., "Deep learning for detecting corona virus disease 2019 (COVID-19) on high-resolution computed tomography: a pilot study," Annals of Translational Medicine, vol. 8, no. 7, 2020.

S. Rajaraman and S. Antani, "Training deep learning algorithms with weakly labeled pneumonia chest x-ray data for covid-19 detection," medRxiv, 2020 Geert Litjens, Thijs Kooi, Babak Ehteshami Bejnordi, Arnaud Arindra Adiyoso Setio, Francesco Ciompi, Mohsen Ghafoorian, Jeroen A.W.M. van der Laak, Bram van Ginneken, Clara I. Sánchez, A survey on deep learning in medical image analysis, Medical Image Analysis,Volume 42,2017,Pages $60-88$

Qu, Liangqiong, et al. “Synthesized 7T MRI from 3T MRI via deep learning in spatial and wavelet domains.” Medical image analysis 62 (2020): 101663.

$\mathrm{Li}$, Wen, et al. "Magnetic resonance image (MRI) synthesis from brain computed tomography (CT) images based on deep learning methods for magnetic resonance (MR)-guided radiotherapy.” Quantitative imaging in medicine and surgery 10.6 (2020): 1223.

Nie, Dong, et al. "Medical image synthesis with deep convolutional adversarial networks.” IEEE Transactions on Biomedical Engineering 65.12 (2018): 2720-2730.

Han, C., Hayashi, H., Rundo, L., Araki, R., Shimoda, W., Muramatsu, S., ... \& Nakayama, H. (2018, April). GAN-based synthetic brain MR image generation. In 2018 IEEE 15th International Symposium on Biomedical Imaging (ISBI 2018) (pp. 734-738). IEEE.

Qiao, Zhi, et al. “CorGAN: Context aware Recurrent Generative Adversarial Network for Medical Image Generation.”2020 IEEE International Conference on Bioinformatics and Biomedicine (BIBM). IEEE, 2020.

Yao, Shuaizhen, et al. "A weighted feature transfer gan for medical image synthesis." Machine Vision and Applications 32.1 (2021): 1-11. 
Jung, Merel M., et al. "Inferring PET from MRI with pix2pix.” Benelux Conference on Artificial Intelligence. Vol. 9. 2018.

Armanious, Karim, et al. "MedGAN: Medical image translation using GANs.” Computerized medical imaging and graphics 79 (2020): 101684.

Jifara, Worku, et al. "Medical image denoising using convolutional neural network: a residual learning approach.” The Journal of Supercomputing 75.2 (2019): 704-718.

Yamashita, Koki, and Konstantin Markov. "Medical Image Enhancement Using Super Resolution Methods.” International Conference on Computational Science. Springer, Cham, 2020.

Raudonis, Vidas, Agne Paulauskaite-Taraseviciene, and Kristina Sutiene. "Fast multi-focus fusion based on deep learning for early-stage embryo image enhancement." Sensors 21.3 (2021): 863.

Li, Meng, et al. "Computed tomography image enhancement using 3D convolutional neural network.” Deep Learning in Medical Image Analysis and Multimodal Learning for Clinical Decision Support. Springer, Cham, 2018. 291-299.

Bera, Sutanu, and Prabir Kumar Biswas. "Noise Conscious Training of Non Local Neural Network Powered by Self Attentive Spectral Normalized Markovian Patch GAN for Low Dose CT Denoising.” IEEE Transactions on Medical Imaging (2021).

Xiaosong Wang, Yifan Peng, Le Lu, Zhiyong Lu, Mohammadhadi Bagheri, and Ronald M Summers. Chestxray8: Hospital-scale chest x-ray database and benchmarks on weakly-supervised classification and localization of common thorax diseases. In Proceedings of the IEEE Conference on Computer Vision and Pattern Recognition, pages 2097-2106, 2017

Clark K, Vendt B, Smith K, et al. The Cancer Imaging Archive (TCIA): maintaining and operating a public information repository. J Digit Imaging. 2013;26:1045-1057.

Menze BH, Jakab A, Bauer S, Kalpathy-Cramer J, Farahani K, Kirby J, Burren Y, Porz N, Slotboom J, Wiest R, Lanczi L, Gerstner E, Weber MA, Arbel T, Avants BB, Ayache N, Buendia P, Collins DL, Cordier N, Corso JJ, Criminisi A, Das T, Delingette H, Demiralp C, Durst CR, Dojat M, Doyle S, Festa J, Forbes F, Geremia E, Glocker B, Golland P, Guo X, Hamamci A, Iftekharuddin KM, Jena R, John NM, Konukoglu E, Lashkari D, Mariz JA, Meier R, Pereira S, Precup D, Price SJ, Raviv TR, Reza SMS, Ryan M, Sarikaya D, Schwartz L, Shin HC, Shotton J, Silva CA, Sousa N, Subbanna NK, Szekely G, Taylor TJ, Thomas OM, Tustison NJ, Unal G, Vasseur F, Wintermark M, Ye DH, Zhao L, Zhao B, Zikic D, Prastawa M, Reyes M, van Leemput K (2015) The multimodal brain tumor image segmentation benchmark (BRATS). IEEE Trans Med Imaging 34:1993-2024. https:/doi. org/10.1109/TMI.2014.237769410.

Bakas S, Reyes M, Jakab A et al (2018) Identifying the best machine learning algorithms for brain tumor segmentation, progression assessment, and overall survival prediction in the BRATS challenge

J. Zhao, Y. Zhang, X. He, P. Xie Covid-ct-dataset: a ct scan dataset about covid-19 (2020) arXiv preprint arXiv:2003.13865

E. Soares, P. Angelov, S. Biaso, M.H. Froes, D.K. Abe Sars-cov-2 ct-scan dataset: a large dataset of real patients ct scans for sars-cov-2 identification medRxiv (2020)

M. Heath, K. Bowyer, D. Kopans, et al., "The Digital Database for Screening Mammography," in Proceedings of the fifth International Workshop on Digital Mammography, M.J. Yaffe, ed., 212-218, Medical Physics Publishing, 2001. ISBN 1-930524-00-5 